\title{
Cognitive parallels between moral judgment and modal judgment
}

\author{
Andrew Shtulman • Lester Tong
}

Published online: 12 April 2013

(C) Psychonomic Society, Inc. 2013

\begin{abstract}
A central question in the study of moral psychology is how immediate intuition interacts with more thoughtful deliberation in the generation of moral judgments. The present study sheds additional light on this question by comparing adults' judgments of moral permissibility with their judgments of physical possibility — a form of judgment that also involves the coordination of intuition and deliberation (Shtulman, Cognitive Development 24:293-309, 2009). Participants $(N=146)$ were asked to judge the permissibility of 16 extraordinary actions (e.g., Is it ever morally permissible for an 80 -year-old woman to have sex with a 20 -year-old man?) and the possibility of 16 extraordinary events (e.g., Will it ever be physically possible for humans to bring an extinct species back to life?). Their tendency to judge the extraordinary events as possible was predictive of their tendency to judge the extraordinary actions as permissible, even when controlling for disgust sensitivity. Moreover, participants' justification and response latency patterns were correlated across domains. Taken together, these findings suggest that modal judgment and moral judgment may be linked by a common inference strategy, with some individuals focusing on why actions/events that do not occur cannot occur, and others focusing on how those same actions/events could occur.
\end{abstract}

Keywords Judgment $\cdot$ Decision making $\cdot$ High-order cognition $\cdot$ Reaction time analysis $\cdot$ Moral psychology

\footnotetext{
A. Shtulman $(\bowtie)$

Department of Psychology, Occidental College,

Los Angeles, CA 90041, USA

e-mail: shtulman@oxy.edu

L. Tong

University of Chicago, Chicago, IL, USA
}

The field of moral psychology has undergone a renaissance in recent years, spurred largely by Haidt's (2001) socialintuitionist model of moral judgment. According to this model, moral judgments are not the product of slow and deliberate reasoning, as had been emphasized in earlier models of moral cognition (Kohlberg, 1981), but the product of fast and automatic intuitions. Explicit reasoning, if it occurs at all, takes the form of post-hoc rationalization, with verbal justifications for moral judgments constituting a consequence, not a cause, of the judgments themselves. Support for this model has come from a growing body of studies demonstrating the primacy of affect and intuition. In one such study, Haidt, Koller, and Dias (1993) asked people of varying ages, cultures, and socioeconomic backgrounds to judge the permissibility of harmless, yet offensive, actions, like cleaning one's toilet with the national flag or eating one's dog after it had been killed in an accident. They found not only that participants' judgments were predicted by their affective reactions, but also that affect was a stronger predictor than appraisals of harm in seven of the 12 subsamples, with most participants denying the permissibility of any action deemed disgusting or disrespectful, regardless of its effect on interpersonal well-being.

These findings, among others (e.g., Greene, Sommerville, Nystrom, Darley, \& Cohen, 2001; Wheatley \& Haidt, 2005), have been taken as evidence that the earlier, Kohlbergian focus on reason and reflection was misguided. Nevertheless, the move from rational models of moral judgment to intuitionist models has seemingly come full circle, with many scholars arguing that intuition alone cannot account for the full range of moral judgments. Lombrozo (2009), for instance, has shown that one's explicit endorsement of a consequentialist philosophy predicts one's stance toward moral dilemmas that pit consequentialist principles against deontological principles, such as the "Trolley problem." Cushman, Young, and Hauser (2006) showed that, in judging the permissibility of 
harmful actions, most adults are consciously aware of at least two moral principles - harm caused by action is worse than harm caused by inaction, and harm caused by physical contact is worse than harm caused at a distance - and their judgments appear to honor those principles. And Zalla, Barlassina, Buon, and Leboyer (2011) have shown that the ability to distinguish harmful actions from harmless, yet offensive, actions is mediated by the ability to appraise intentional action and discern the welfare of others.

While these studies suggest a role for explicit, deliberate reasoning in moral judgment, they have focused on such processes within the context of the moral judgments themselves. That is, their measures of explicit reasoning are not wholly independent of the judgments that they purport to explain. One notable exception is a recent study by Cushman and Young (2011), comparing how individuals evaluate events involving trade-offs in human lives with how they evaluate structurally analogous, but nonmoral, events involving trade-offs in material outcomes. Cushman and Young showed that moral judgments track both causal attribution (i.e., attributions of whether or not the protagonist caused the events to transpire) and intentional attribution (i.e., attributions of whether or not the protagonist intended the events to transpire). But are causal and intentional attribution the only forms of nonmoral cognition tracked by moral judgments? Might there be other forms further downstream, after causality and intentionality have been assessed? In the present study, we explored this possibility by comparing participants' moral judgments to their judgments in a conceptually distinct, yet logically related, domain: physical possibility. Our rationale for making a comparison between the moral and modal domains was threefold.

First, modal judgment appears to share many of the same computational demands as moral judgment. Just as violations of social norms (e.g., eating one's dog) often elicit immediate intuitions ("that's not OK!") that may be modified or rejected on the basis of further reflection ("well, if the dog is already dead ..."; Greene \& Haidt, 2002), violations of empirical regularities appear to produce a similar chain of reasoning (Shtulman, 2009). For instance, hypothetical events, like living for 200 years or traveling beyond the Milky Way, likely elicit the immediate intuition that such events are impossible, given that neither has occurred nor is likely to occur anytime soon. But further deliberation-for instance, deliberations about genetics and medicine, in the case of human longevity, or deliberations about spacecrafts and wormholes, in the case of extraterrestrial travel-may ultimately lead to the conclusion that such events are possible. In this way, both modal judgment and moral judgment appear to require the coordination of immediate intuition, derived through automatic semantic or episodic associations, and more considered reflection in light of one's (explicitly known) empirical and theoretical commitments.
There is, however, one significant difference between the two forms of judgment, which is that only moral judgment appears to be grounded in emotion as well. Indeed, psychologists have identified a number of emotions that seem to be specifically "moral" in nature, including guilt, shame, gratitude, and contempt (Haidt, 2003). While there has been no documentation, to our knowledge, of a corresponding suite of "modal emotions," such emotions, if they do exist, would seem to play a less significant role in modal judgment than the role played by emotion in moral judgment (Russell \& Giner-Sorolla, 2011; Strohminger, Lewis, \& Meyer, 2011). Thus, common patterns of reasoning across the two domains might help determine the proportion of variance in moral judgment that can be accounted for by seemingly nonaffective processes.

Second, consistent with the computational similarities outlined above, the modal and moral domains share linguistic similarities as well. Virtually all languages make a lexical distinction between factual claims, expressed with auxiliary verbs like "is" and "does," and modal claims, expressed with auxiliary verbs like "could" and "should" (Boyd \& Thorne, 1969; Perkins, 1983). Whereas factive auxiliaries are used to express assertions of truth, modal auxiliaries are used to express assertions of possibility or permissibility. The validity of such assertions cannot be evaluated empirically, but must instead be evaluated against a set of preexisting commitments or principles. The claim "it could rain," for instance, is not a claim about current weather conditions, verifiable by direct observation, but a claim about the possibility of rain, given certain preconditions (e.g., cloudy skies). Philosophers have long noted logical relations between alethic modality, or the domain of possibility and necessity, and deontic modality, or the domain of permissibility and obligation (see Hughes \& Cresswell, 1968), but the psychological relations among these domains have not been well studied.

Third, psychologists have documented similar developmental trajectories in the modal and moral domains. Specifically, researchers have found that young children have a more parochial sense of both what is possible and what is permissible than do older children and adults. In the modal domain, young children are less likely than older children to affirm the possibility of events that violate empirical regularities but not physical laws, like catching a fly with chopsticks or finding an alligator under the bed (Shtulman, 2009; Shtulman \& Carey, 2007). In the moral domain, young children are also less likely than older children to affirm the permissibility of actions that violate social conventions but not moral prescriptions, like singing "Jingle Bells" at a birthday party or wearing pajamas to school (Browne \& Woolley, 2004; Kalish, 1998; Komatsu \& Galotti, 1986). Both differences have tentatively been explained in terms of children's developing sensitivity to the limitations of their 
own experiences and intuitions. That is, children initially appear to judge anything that defies expectation as impossible or impermissible, but gradually come to reflect on the validity of those intuitions prior to passing judgment (see Shtulman, 2009; Woolley \& Ghossainy, in press). It remains an open question, however, whether commonalities in modal development and moral developmental arise from a common source-for instance, a shared inference strategy - or are merely coincidental.

In short, there are both theoretical and empirical reasons for comparing moral judgment to modal judgment, the most important being that shared variance across the two domains might indicate a common form of reasoning. We undertook this comparison by eliciting judgments and justifications for events that are empirically infrequent (or nonexistent) but do not violate any commonly known physical laws or moral prescriptions. Our prediction was that individuals who were open to the possibility of many extraordinary events would also be open to the permissibility of many extraordinary actions and would justify their judgments differently than those who were more skeptical across the board.

\section{Method}

\section{Participants}

The participants were 146 college undergraduates recruited from introductory psychology courses in exchange for extra credit. One additional participant was tested but excluded from the final analyses on account of answering all questions "yes" (a statistically deviant response pattern).

\section{Procedure}

The participants were presented 16 yes-or-no questions about physical possibility and 16 yes-or-no questions about moral permissibility in MediaLab v1.21. Their response latencies were recorded, although participants were not explicitly apprised of the fact that judgments were being timed. The number of characters in each question varied minimally, from 90 to 99 , and the ordering of the 32 questions was randomized across participants in order to control for practice effects. Response latencies more than two standard deviations from the mean were removed from the data set $(3.6 \%$ in total).

All questions about physical possibility took the form "Will it ever be physically possible for humans to [event]?" and all questions about moral permissibility took the form "Is it ever morally permissible for [actor] to [action]?" The extraordinary actions, which are listed in Table 1 in decreasing order of perceived permissibility, were intended to be potentially but not patently immoral (i.e., prohibited by
Table 1 The 16 offensive actions, ordered by the percentages of participants who judged them as permissible

\begin{tabular}{lr} 
Is it ever morally permissible for a $(n) \ldots$ & $\%$ \\
\hline College student to attend class in her flannel pajamas? & 98 \\
Roommate to drink milk directly from the milk container? & 85 \\
Medical examiner to dissect the corpse of his deceased mother? & 84 \\
80-year-old woman to have sex with a 20-year-old man? & 83 \\
Young man to wear the same underwear for weeks at a time? & 80 \\
Wealthy man to spend all day, every day, smoking marijuana? & 77 \\
Dinner guest to spit in his water glass before taking a drink? & 73 \\
Chef to use a sterilized flyswatter as a cooking utensil? & 73 \\
Dog owner to eat her dog after it has been killed by a car? & 59 \\
Janitor to use an American flag as a rag for cleaning toilets? & 56 \\
Woman to replace a borrowed necklace with an identical copy? & 52 \\
Man to masturbate with a dead chicken before cooking it? & 48 \\
Young woman to give her brother an open-mouthed kiss? & 48 \\
Person with no family to commit suicide out of boredom? & 35 \\
Couple to kidnap an infant and raise it as their own child? & 22 \\
Husband to kill his wife in order to collect life insurance? & 7 \\
\hline
\end{tabular}

harm norms), like spitting in one's glass before taking a drink or replacing a borrowed necklace with an identical copy. Half were taken from previous studies involving offensive, yet harmless, actions (Haidt, McCauley, \& Rozin, 1994; Haidt et al., 1993; Nichols, 2002), and half were created from scratch. The extraordinary events, which are listed in Table 2 in decreasing order of perceived possibility, were intended to be potentially but not patently impossible (i.e., prohibited by physical laws), like resuscitating a person frozen for many years or teleporting an object to a distant location. Some were taken from previous research on modal judgment (Shtulman, 2009; Shtulman \& Carey, 2007), but most were created from scratch. All items were pretested with an undergraduate sample to ensure that they elicited variable judgments.

It bears mentioning that a handful of the items in each domain did not conform to these criteria. Rather, they were selected to be unambiguously possible (e.g., powering a car exclusively with solar energy), unambiguously permissible (e.g., attending class in one's pajamas), unambiguously impossible (e.g., catching and holding a shadow), and unambiguously impermissible (e.g., killing one's wife to collect her life insurance), so as to prevent participants from adopting a "yes" bias or a "no" bias. Nevertheless, participants' judgments varied even on these "control" items, so they were included in the final analyses as well.

Following the modal/moral judgment task, participants were administered two instruments that have been shown to be predictive of moral judgment in prior research: Haidt et al.'s (1994) Disgust Scale (see Nichols, 2002; Wheatley \& Haidt, 2005), and Cacioppo and Petty's (1982) Need for 
Table 2 The 16 extraordinary events, ordered by the percentages of participants who judged them as possible

\begin{tabular}{lr}
\hline Will it ever be physically possible for humans to ... & $\%$ \\
\hline Power a car exclusively with solar energy? & 100 \\
Perform a successful brain transplant? & 84 \\
Travel to galaxies beyond the Milky Way? & 73 \\
Live to the age of 200 years or greater? & 70 \\
Bring an extinct species back to life? & 57 \\
Resuscitate a person frozen for many years? & 54 \\
Travel safely at the speed of light? & 44 \\
Teleport an object to a distant location? & 44 \\
Download knowledge directly into the brain? & 40 \\
Create a completely invisible cloth? & 40 \\
Directly access someone else's thoughts? & 38 \\
Levitate, unsupported, above the ground? & 24 \\
Shrink a person to one-tenth their size? & 23 \\
Completely reverse the aging process? & 20 \\
Travel through time back into the past? & 18 \\
Catch and hold a shadow in their hands? & 4 \\
\hline
\end{tabular}

Cognition Scale (see Bartels, 2008). Our purpose in administering these instruments was to determine whether the predictor variable of interest - participants' modal judgments - could explain some of the variance in their moral judgments beyond that explained by these instruments alone. The ordering of the instruments was randomized across participants, as was the ordering of their items.

\section{Coding}

In addition to making yes-or-no judgments, participants also justified their judgments, generating a total of 4,672 justifications (one justification per each of 32 judgments for 146 participants). These justifications were sorted into one of three categories: conditional, principled, or redundant. Conditional justifications referenced specific circumstances under which the target item would (or would not) be possible or permissible. Principled justifications referenced general principles of a physical or social nature that the target item either violated or satisfied. Finally, redundant justifications elaborated on, but did not actually justify, the judgment in question.

To illustrate, consider the following justifications for why it is morally permissible for an 80-year-old woman to have sex with a 20-year-old man: "Both parties are of legal age" and "sex is a private affair" were coded as principled; "if they love each other" and "if they both consent" were coded as conditional; and "it's disturbing but not immoral" and "socially weird but morally fine" were coded as redundant. Likewise, consider the following justifications for why it is physically possible for humans to perform a successful brain transplant: "The brain is just one of many organs" and "It is a simple physical relocation" were coded as principled; "if we develop the right kind of life support" and "if it weren't rejected by the recipient" were coded as conditional; and "given enough time anything is possible" and "I don't see why not" were coded as redundant.

Importantly, all three categories could be applied to justifications in both domains (modal and moral) and for both types of judgment (affirmative and negative). Two trained coders applied the coding scheme to all 4,672 justifications independently. The overall agreement was $84 \%$ (Cohen's kappa $=.76)$, and disagreements were resolved by a third coder. In total, $47 \%$ of justifications were coded as conditional, $38 \%$ as principled, and $15 \%$ as redundant.

\section{Results \\ Judgment patterns}

As anticipated, participants varied in both the number of events judged possible (range $=2$ to $15, M=7.3, S D=3.0$ ) and the number of actions judged permissible (range $=2$ to $16, M=9.8, S D=3.0$ ). The former comprised participants' modal judgment score, and the latter their moral judgment score. Pearson's correlations revealed that moral judgment scores were positively correlated with modal judgment scores $(r=.34, p<.001)$, negatively correlated with Disgust Scale (DS) scores $(r=-.45, p<.001)$, and uncorrelated with Need for Cognition Scale (NCS) scores $(r=.11$, n.s.).

To determine whether the effects of modal judgment and disgust sensitivity were additive or interactive, we sorted participants into four groups on the basis of whether their modal judgment score was above or below the median score of 7 (on a scale from 0 to 16) and whether their DS score was above or below the median score of 2.0 (on a scale from 1.0 to 3.0). The moral judgment scores for these four groups are displayed in Fig. 1. A repeated measures analysis of variance (ANOVA) revealed significant main effects of both modal judgment $[F(1,142)=7.58, p<.01]$ and disgust sensitivity $[F(1,142)=14.85, p<.001]$, but no interaction between them $[F(1,142)<1]$, indicating that modal judgment predicted moral judgment at both high and low levels of disgust sensitivity. Consistent with this analysis, we found that the correlation between modal judgment scores and moral judgment scores in the full sample remained significant, even after controlling for DS scores (partial $r=.22, p<.01$ ).

One additional analysis was conducted to explore the possibility that the effects documented in Fig. 1 were driven by a distinct subset of the moral items. These items were, after all, quite diverse, ranging from violations of authority (e.g., using an American flag as a rag) to violations of purity 


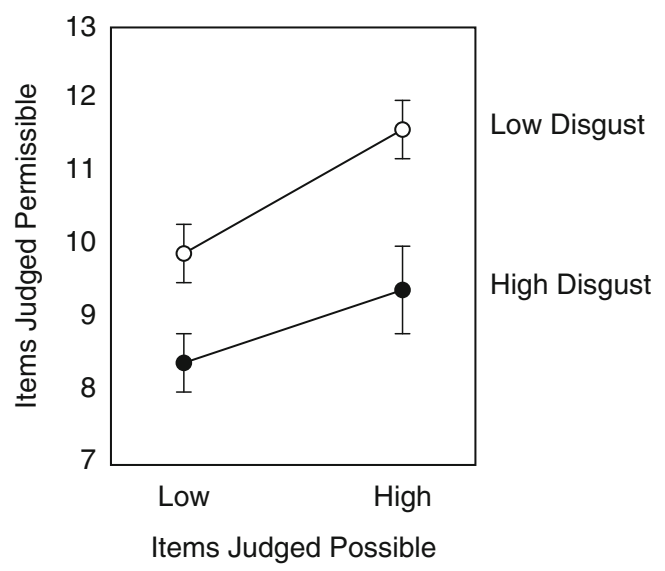

Fig. 1 Mean numbers of extraordinary actions judged as permissible $( \pm S E)$ as a function of (a) disgust sensitivity and (b) the disposition to judge extraordinary events as possible

(e.g., masturbating with a dead chicken) to violations of sacred values (e.g., committing suicide out of boredom). Relations between moral judgments and the three predictor variables - modal judgment scores, DS scores, and NCS scores - were thus analyzed separately for each item, as is shown in Table 3. These correlations were point-biserial, given that responses to each item were dichotomous ("yes" vs. "no"), which rendered them potentially more volatile than the Pearson's correlations noted above. That said, the correlations between moral judgments and modal judgments were consistently positive, with eight (out of 16) reaching statistical significance, and the correlations between moral judgments and DS scores were consistently negative, with 11 reaching statistical significance. The correlations between moral judgments and NCS scores, on the other hand, hovered near zero, with none reaching statistical significance. Thus, the effects at hand do not appear to be restricted to one, and only one, category of moral consideration, although future research will be needed to determine whether some categories of moral consideration are more strongly associated with modal judgments than are others.

\section{Justification patterns}

Justifications for modal and moral judgments were correlated across domains in two ways. First, they were correlated in terms of frequency: The more often that participants provided a particular type of justification in one domain, the more often they provided the same type of justification in the other domain (for conditional, $r=.29, p<.001$; for principled, $r=.29, p<.001$; for redundant, $r=.44, p<.001)$. Second, the justifications were correlated in terms of function: The more often participants made either affirmative ("yes") or negative ("no") judgments, the more often they provided particular types of justifications. Specifically, conditional justifications were positively correlated with affirmative judgments in both domains (modal
Table 3 Point-biserial correlations between affirmative judgments for the 16 offensive actions and (a) modal judgment scores, (b) disgust sensitivity scores, and (c) need-for-cognition scores

\begin{tabular}{|c|c|c|c|}
\hline Offensive Action & $\begin{array}{l}\text { Modal } \\
\text { Judgment }\end{array}$ & $\begin{array}{l}\text { Disgust } \\
\text { Sensitivity }\end{array}$ & $\begin{array}{l}\text { Need for } \\
\text { Cognition }\end{array}$ \\
\hline Wearing pajamas to class & .11 & $-.18^{*}$ & -.04 \\
\hline Drinking milk from carton & -.05 & -.06 & -.06 \\
\hline Autopsy of mother's corpse & .01 & -.14 & .01 \\
\hline $\begin{array}{l}80 \text { - and } 20 \text {-year-old } \\
\text { having sex }\end{array}$ & $.17^{*}$ & $-.20^{*}$ & .08 \\
\hline Rarely changing underwear & .13 & $-.18^{*}$ & -.01 \\
\hline $\begin{array}{l}\text { Smoking marijuana } \\
\text { every day }\end{array}$ & $.18^{*}$ & -.14 & -.04 \\
\hline Spitting in drinking glass & $.19^{*}$ & $-.27^{* *}$ & .02 \\
\hline Cooking with flyswatter & .11 & -.15 & .11 \\
\hline Eating one's dog & $.19^{*}$ & $-.25^{* *}$ & .01 \\
\hline Using American flag as a rag & $.23^{* *}$ & $-.33^{* *}$ & .15 \\
\hline Replacing borrowed necklace & .03 & -.02 & .08 \\
\hline $\begin{array}{l}\text { Masturbating with dead } \\
\text { chicken }\end{array}$ & .12 & $-.33^{* *}$ & .12 \\
\hline French kissing one's sibling & $.20^{*}$ & $-.34^{* *}$ & .10 \\
\hline $\begin{array}{l}\text { Committing suicide } \\
\text { out of boredom }\end{array}$ & $.24^{* *}$ & $-.24^{* *}$ & -.03 \\
\hline $\begin{array}{l}\text { Kidnapping someone } \\
\text { else's child }\end{array}$ & .12 & $-.17^{*}$ & .15 \\
\hline $\begin{array}{l}\text { Killing one's spouse } \\
\text { for insurance }\end{array}$ & $.32^{* *}$ & $-.20^{*}$ & .06 \\
\hline
\end{tabular}

domain, $r=.59, p<.001$; moral domain, $r=.48, p<.001$ ), and principled justifications were positively correlated with negative judgments in both domains (modal domain, $r=.51$, $p<.001$; moral domain, $r=.36, p<.001)$. In other words, the more often that participants judged items as possible or permissible, the more often they provided conditional justifications for those judgments, and the more often that participants judged items as impossible or impermissible, the more often they provided principled justifications for those judgments. Redundant justifications were not significantly correlated with either type of judgment.

These effects can be seen in Fig. 2, which depicts the frequencies of conditional and principled justifications as a function of modal and moral judgment scores (where "low" corresponds to a below-median, and "high" to an above-median, number of affirmative judgments). Although the overall frequencies of each justification type differ by domain, the interactions between justification type and judgment score are similar across domains. A pair of repeated measures ANOVAs, in which Justification Type (conditional vs. principled) was treated as a within-participants factor and Judgment Score (low vs. high) was treated as a between-participants factor, confirmed that the interaction between justification type and judgment score was significant in both the modal domain 
$[F(1,144)=135.51, p<.001]$ and the moral domain $[F(1,144)=12.84, p<.001]$. Thus, participants who were disposed to provide different types of judgments also appeared to be disposed to provide different types of justification.

One concern with this interpretation is that certain judgments may lend themselves better to certain types of justification. In particular, affirmative judgments may be easier to justify by a condition than by a principle, and negative judgments may be easier to justify by a principle than by a condition. To rule out this possibility, we separated the justifications provided for affirmative judgments from those provided for negative judgments and reran the ANOVAs described above. These analyses revealed significant interactions between justification type and judgment score, even for judgments of the same type [modal domain and affirmative judgments, $F(1,144)=13.94, p<.001$; modal domain and negative judgments, $F(1,144)=$ $12.43, p<.001$; moral domain and affirmative judgments, $F(1,144)=81.65, p<.001$; moral domain and negative judgments, $F(1,144)=48.54, p<.001]$. The interactions displayed in Fig. 2 do not, therefore, merely reflect a coincidental association between certain types of judgments and certain types of justifications.

\section{Response latency patterns}

On average, participants took $9.4 \mathrm{~s}$ to make their modal judgments $(S D=5.2)$ and $9.4 \mathrm{~s}$ to make their moral judgments $(S D=5.1)$, and there was no relation between the type of judgment made (affirmative vs. negative) and the speed of that judgment in either domain. However, an interaction was observed between judgment type and judgment score, as is shown in Fig. 3: Participants with "low" judgment scores took longer to make affirmative than to make negative judgments, and participants with "high" judgment scores took longer to make negative than to make affirmative judgments. The statistical reliability of these interactions was confirmed with repeated measures ANOVAs in which Judgment Type (affirmative vs. negative) was treated as a withinparticipants factor and Judgment Score (low vs. high) was treated as a between-participants factor [modal domain, $F(1$, $144)=6.54, p<.05$; moral domain, $F(1,144)=4.33, p<.05]$. Generating judgments that ran counter to one's typical judgment pattern thus appeared to take additional cognitive effort, regardless of whether that pattern was to judge items as predominantly possible/permissible or to judge them as predominantly impossible/impermissible.

\section{Discussion}

Assertions of possibility and permissibility overlap in their linguistic expressions (Perkins, 1983) and logical forms (Hughes \& Cresswell, 1968), but do they also overlap in any genuine psychological respects? Our findings suggest that they do. Using extraordinary events to elicit modal judgments and extraordinary actions to elicit moral judgments, we found that the more often that participants judged the extraordinary events as possible, the more often they judged the extraordinary actions as permissible, irrespective of their disgust sensitivity. Moreover, judgments in both domains were predicted by similar patterns of justification and similar patterns of response latencies. That is, the disposition to judge the items at hand as possible or permissible was associated with (a) an increased provision of conditional justifications, (b) a decreased provision of principled justifications, and (c) longer response times for the judgments of impossibility or impermissibility. In contrast, the disposition to judge those same items as impossible or impermissible was associated with (a) an increased provision of principled justifications, (b) a decreased provision of conditional justifications, and (c) longer response times for judgments of possibility or permissibility.
Fig. 2 Mean numbers of principled and conditional justifications provided in each domain (left, items judged possible; right, items judged permissible) $( \pm S E)$ as a function of the disposition to judge items in that domain as possible or permissible
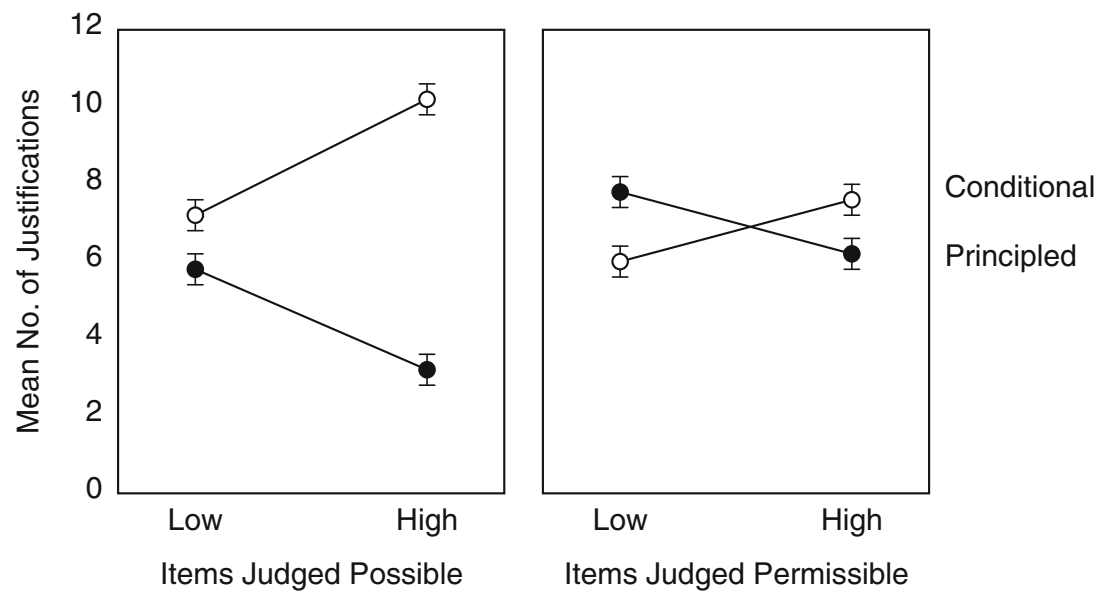
Fig. 3 Mean response times for affirmative and negative judgments in each domain (left, items judged possible; right, items judged permissible) $( \pm S E)$ as a function of the disposition to judge items in that domain as possible or permissible

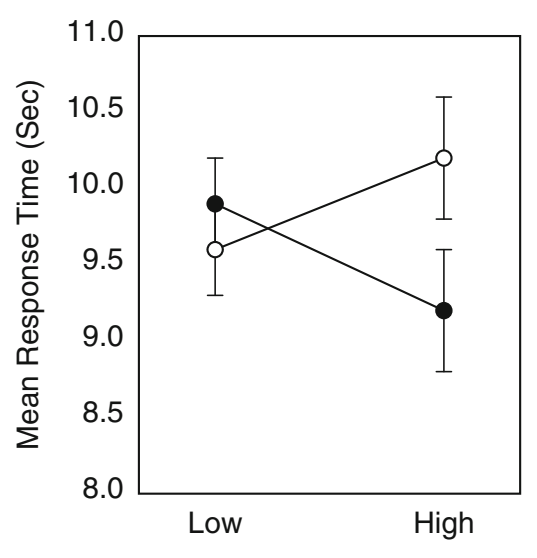

Items Judged Possible

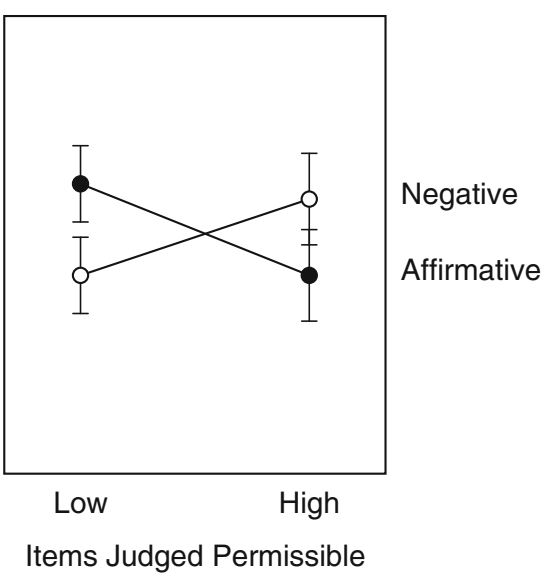

To provide more of a flavor for these findings, consider the difference between Participant 48 , who judged $75 \%$ of the modal items as possible and $81 \%$ of the moral items as permissible, and Participant 141 , who judged only $38 \%$ of the modal items as possible and only $13 \%$ of the moral items as permissible. For the event of traveling at the speed of light, Participant 48 claimed this event was possible, justifying it with the conditional justification "the trick is to find a fuel source that can get us to that speed and maintain it for long travels," whereas Participant 141 claimed that this event was impossible, justifying it with the principled justification "the human body cannot handle the speed." For the action of using a sterile flyswatter as a cooking utensil, Participant 48 claimed that this event was permissible, justifying it with the conditional justification "as long as he hadn't killed any flies with it," whereas Participant 141 claimed this event was impermissible, justifying it with the principled justification "its function is only to hit flies." In the seven instances that Participant 48 judged an item to be impossible or impermissible, she took an average of $4.4 \mathrm{~s}$ longer to do so, and in the eight instances that Participant 141 judged an item to be possible or permissible, she took an average of $5.7 \mathrm{~s}$ longer to do so.

As a whole, these findings suggest that modal judgment and moral judgment may be linked by differences in one's overall approach to the evaluation of nonfactual claims. While some individuals appear to focus on why certain events and actions that do not occur cannot occur, others appear to focus on how those same actions and event could occur. Whereas the former group tend to identify general principles that would preclude the events' possibility or undermine the actions' permissibility, the latter tend to identify specific conditions that would facilitate the events' possibility or justify the actions' permissibility. This interpretation of the data not only makes sense of the close correspondence between modal judgments and moral judgments (Fig. 1), but also makes sense of the divergence in justification patterns (Fig. 2) and response latency patterns
(Fig. 3) between those with high modal/moral judgment scores and those with low modal/moral judgment scores.

Of course, given that our methods were correlational in nature, we must acknowledge the possibility that the observed correlations may have been mediated by a third, yet-to-be-determined variable. "Need for cognition" does not seem to be that variable, given its lack of association with participants' moral judgment scores, yet other possibilities include openness to experience (McCrae \& Costa, 1987), cognitive reflectiveness (Frederick, 2005), or open-mindedness (Kruglanski, 2004). Certainly, the act of accepting extraordinary events as possible and extraordinary actions as permissible would seem to require degrees of both open-mindedness and cognitive reflection, but it remains an empirical question whether the relation between moral judgment and modal judgment can be fully explained by such variables. The mere observation that modal judgment and moral judgment share similar computational demands, as described above, suggests that these two forms of judgment should track one another more closely than either should track a conceptually distinct ability or disposition.

Another possible mediator of the relation between modal judgment and moral judgment is one's beliefs about "natural order" or "divine will" (Brandt \& Reyna, 2011; Morewedge $\&$ Clear, 2008). Such beliefs might lead one to deny both the possibility of extraordinary events and the permissibility of extraordinary actions because those things would appear to be forbidden by God (or some other form of supernatural agency). In other words, participants who made mostly "no" judgments may have been motivated by the explicit belief that, if God had intended such things to occur, then they would occur, regularly and without question. While the data at hand cannot rule out this explanation, there are at least two reasons to doubt it. First, participants rarely appealed to religious considerations in their justifications; only ten justifications out of 4,672 referenced any overt religious content. Second, it is unclear how differences in religious belief could explain the full range of findings documented here. 
That is, if participants who made mostly "no" judgments did so on the basis of religious considerations, what considerations might have guided those who made mostly "yes" judgments? And why did those considerations yield opposite patterns of justification and response latency, as opposed to no pattern whatsoever? Such details imply that "yes" judgments were based on something more substantive than the mere absence of religious belief.

Alternative explanations aside, the basic finding that questions about physical possibility and moral permissibility yield similar patterns of judgment, justification, and response latency has potentially important implications for the study of both forms of cognition. With respect to modal cognition, our findings imply that differences in modal judgment do not necessarily reduce to differences in knowledge or experience. The participants in our study came from a rather homogeneous population in terms of modality-relevant knowledge (i.e., basic principles of science), yet they drew vastly different modal inferences. No two participants produced the same pattern of judgments, and the difference between participants could be as large as $81 \%$. The implication is that individuals with similar types of knowledge or experience may still form different modal judgments, as determined by how they coordinate that knowledge with their intuition (see also Nichols, 2006; Weisberg \& Sobel, 2012). That said, we did not explicitly measure participants' physical or biological knowledge, so additional studies will be needed to verify that differences in content knowledge are not sufficient to explain differences in modal judgments.

With regard to moral cognition, our findings imply that differences in moral judgments do not necessarily reduce to differences in intuition, particularly affective intuition. Participants with similar affective responses to the items on the Disgust Scale still varied in their moral judgments, and a significant portion of that variance was accounted for by their judgment patterns in the structurally similar, yet less affectively charged, modal domain. These findings resonate with a growing body of research demonstrating that affective intuition is not the only component of moral judgment (e.g., Huebner, Dwyer, \& Hauser, 2009; Nichols \& Mallon, 2006; Pizzaro \& Bloom, 2003). Explicit reasoning may play an important role as well, particularly in situations in which one's immediate intuition would appear to belie a more principled set of commitments and beliefs. Of course, further research will be needed to determine whether the patterns of reasoning tapped by the modal judgment task are truly explicit in nature. Manipulating the time constraints under which participants make their judgments would be one way to investigate this claim, as the relation between modal judgment and moral judgment should weaken if deliberate reasoning is precluded. Another possibility would be to manipulate participants' affective states, in terms of either their general mood (à la Valdesolo \& DeSteno, 2006) or their feelings of disgust in particular (à la Rottman \& Kelemen, 2012), and to assess whether the relation between modal judgment and moral judgment is weaker under these conditions, as well.

Perhaps the most important contribution of this research is the introduction of a new means of comparison for analyzing the form and function of moral judgment. To date, moral judgment has been studied most extensively in the context of the "trolley problem" (e.g., Bartels, 2008; Cushman et al., 2006; Greene et al., 2001; Lombrozo, 2009; Moore, Clark, \& Kane, 2008; Paxton, Ungar \& Greene 2012; Pellizzoni, Siegal, \& Surian, 2010; Suter \& Hertwig, 2011), yet the tension tapped by this problemthe tension between deontic and utilitarian modes of decision making - is clearly not the only issue of interest to moral psychologists. It would thus be ideal to identify measures of moral cognition that can be applied to other forms of moral judgment, including judgments about lying (e.g., Perkins \& Turiel, 2007), judgments about punishment (e.g., Descioli \& Kurzban, 2009), and judgments about fairness (e.g., Stephen \& Pham, 2008). Patterns of modal judgment and modal justification may provide such a measure. Not only are they empirically tractable, but they also help further the goal of connecting moral judgment to human cognition more generally, such that moral judgment is studied not as a unique type of judgment, independent of all others, but as one of many types requiring the coordination of prior commitments and current intuitions.

Author note We would like to thank Sarah Berkoff, William Krause, and Tori Leon for assistance with data collection and data analysis.

\section{References}

Bartels, D. M. (2008). Principled moral sentiment and the flexibility of moral judgment and decision making. Cognition, 108, 381-417.

Boyd, J., \& Thorne, J. P. (1969). The semantics of modal verbs. Journal of Linguistics, 5, 57-74.

Brandt, M. J., \& Reyna, C. (2011). The chain of being: A hierarchy of morality. Perspectives on Psychological Science, 6, 428-446.

Browne, C. A., \& Woolley, J. D. (2004). Preschoolers' magical explanations for violations of physical, social, and mental laws. Journal of Cognition and Development, 5, 239-260.

Cacioppo, J. T., \& Petty, R. E. (1982). The need for cognition. Journal of Personality and Social Psychology, 42, 116-131.

Cushman, F., \& Young, L. (2011). Patterns of moral judgment derive from non-moral psychological representations. Cognitive Science, 35, 1052-1075.

Cushman, F., Young, L., \& Hauser, M. (2006). The role of conscious reasoning and intuition in moral judgment: Testing three principles of harm. Psychological Science, 17, 1082-1089.

DeScioli, P., \& Kurzban, R. (2009). Mysteries of morality. Cognition, 112, 281-299. 
Frederick, S. (2005). Cognitive reflection and decision making. Journal of Economic Perspectives, 19, 25-42.

Greene, J., \& Haidt, J. (2002). How (and where) does moral judgment work? Trends in Cognitive Sciences, 6, 517-523. doi:10.1016/ S1364-6613(02)02011-9

Greene, J. D., Sommerville, R. B., Nystrom, L. E., Darley, J. M., \& Cohen, J. D. (2001). An fMRI investigation of emotional engagement in moral judgment. Science, 293, 2105-2108. doi:10.1126/ science. 1062872

Haidt, J. (2001). The emotional dog and its rational tail: A social intuitionist approach to moral judgment. Psychological Review, $108,814-834$.

Haidt, J. (2003). The moral emotions. In R. J. Davidson, K. R. Scherer, \& H. H. Goldsmith (Eds.), Handbook of affective sciences (pp. 852-870). Oxford, UK: Oxford University Press.

Haidt, J., Koller, S., \& Dias, M. G. (1993). Affect, culture, and morality, or Is it wrong to eat your dog? Journal of Personality and Social Psychology, 65, 613-628.

Haidt, J., McCauley, C., \& Rozin, P. (1994). Individual differences in sensitivity to disgust: A scale sampling seven domains of disgust elicitors. Personality and Individual Differences, 16, 701-713.

Huebner, B., Dwyer, S., \& Hauser, M. (2009). The role of emotion in moral psychology. Trends in Cognitive Sciences, 13, 1-6. doi:10.1016/j.tics.2008.09.006

Hughes, G., \& Cresswell, M. (1968). An introduction to modal logic. London, UK: Methuen.

Kalish, C. (1998). Reasons and causes: Children's understanding of conformity to social rules and physical laws. Child Development, 69, 706-720.

Kohlberg, L. (1981). Essays on moral development, Vol. I: The philosophy of moral development. San Francisco, CA: Harper \& Row.

Komatsu, L. K., \& Galotti, K. M. (1986). Children's reasoning about social, physical, and logical regularities. Child Development, 57, 413-420.

Kruglanski, A. W. (2004). The psychology of closed mindedness. New York, NY: Psychology Press.

Lombrozo, T. (2009). The role of moral commitments in moral judgment. Cognitive Science, 33, 273-286.

McCrae, R. R., \& Costa, P. T. (1987). Validation of the five-factor model of personality across instruments and observers. Journal of Personality and Social Psychology, 52, 81-90.

Moore, A. B., Clark, B. A., \& Kane, M. J. (2008). Who shalt not kill? Individual differences in working memory capacity, executive control, and moral judgment. Psychological Science, 19, 549-557.

Morewedge, C. K., \& Clear, M. E. (2008). Anthropomorphic God concepts engender moral judgment. Social Cognition, 26, 182-189.

Nichols, S. (2002). Norms with feeling: Towards a psychological account of moral judgment. Cognition, 84, 221-236.

Nichols, S. (2006). Imaginative blocks and impossibility: An essay in modal psychology. In S. Nichols (Ed.), The architecture of the imagination (pp. 237-255). Oxford, UK: Oxford University Press.

Nichols, S., \& Mallon, R. (2006). Moral dilemmas and moral rules. Cognition, 100, 530-542.

Paxton, J. M., Ungar, L., \& Greene, J. D. (2012). Reflection and reasoning in moral judgment. Cognitive Science, 36, 163-177.

Pellizzoni, S., Siegal, M., \& Surian, L. (2010). The contact principle and utilitarian moral judgments in young children. Developmental Science, 13, 265-270.

Perkins, M. (1983). Modal expressions in English. London, UK: Pinter.

Perkins, S. A., \& Turiel, E. (2007). To lie or not to lie: To whom and under what circumstances. Child Development, 78, 609621.

Pizzaro, D. A., \& Bloom, P. (2003). The intelligence of the moral intuitions: Comment on Haidt (2001). Psychological Review, 110, 193-196.

Rottman, J., \& Kelemen, D. (2012). Aliens behaving badly: Children's acquisition of novel purity-based morals. Cognition, 124, 356360.

Russell, P. S., \& Giner-Sorolla, R. (2011). Moral anger is more flexible than moral disgust. Social Psychological and Personality Science, 2, 360-364.

Shtulman, A. (2009). The development of possibility judgment within and across domains. Cognitive Development, 24, 293-309.

Shtulman, A., \& Carey, S. (2007). Improbable or impossible? How children reason about the possibility of extraordinary claims. Child Development, 78, 1015-1032.

Stephen, A. T., \& Pham, M. T. (2008). On feelings as a heuristic for making offers in ultimatum negotiations. Psychological Science, 19, 1051-1058.

Strohminger, N., Lewis, R. L., \& Meyer, D. E. (2011). Divergent effects of different positive emotions on moral judgment. Cognition, 119, 295-300.

Suter, R. S., \& Hertwig, R. (2011). Time and moral judgment. Cognition, 119, 454-458.

Valdesolo, P., \& DeSteno, D. (2006). Manipulations of emotional context shape moral judgment. Psychological Science, 17, 476477.

Weisberg, D. S., \& Sobel, D. M. (2012). Young children discriminate improbable from impossible events in fiction. Cognitive Development, 27, 90-98.

Wheatley, T., \& Haidt, J. (2005). Hypnotic disgust makes moral judgments more severe. Psychological Science, 16, 780-784.

Woolley, J. D., \& Ghossainy, M. E. (2013). Revisiting the fantasyreality distinction: Children as naïve skeptics. Child Development. doi:10.1111/cdev.12081

Zalla, T., Barlassina, L., Buon, M., \& Leboyer, M. (2011). Moral judgment in adults with autism spectrum disorders. Cognition, 121, 115-126. 